\title{
Investigation of the Turbulent Schmidt Number Effects On Numerical Modelling Of Vortex-Type Stormwater Retention Ponds
}

\author{
S. M. Yamini ${ }^{1}$; H. Shamloo ${ }^{2}$; S. H. Ghafari ${ }^{3}$ \\ ${ }^{1}$ M.Eng., Dep. of Civil Engineering \\ K.N. Toosi University of Technology, Valiasr St., Tehran, Iran. \\ smyamini@alumni.kntu.ac.ir \\ ${ }^{2}$ Associate Professor, Dep. of Civil Engineering \\ K.N. Toosi University of Technology, Valiasr St., Tehran, Iran. \\ hshamloo@kntu.ac.ir \\ ${ }^{3} \mathrm{Ph} . \mathrm{D}$. , Dep. of Civil Engineering \\ Univ. of Tehran, Enqelab St., Tehran, Iran. \\ sarvenazghafari@ut.ac.ir
}

\begin{abstract}
Achieving accurate and reliable CFD modelling results often is the subject of scrutiny because of the importance of the inputs in those simulations. If turbulence modelling is based on Reynolds-Averaged Navier-Stokes (RANS) equations, estimating the turbulent scalar transport requires the definition of the turbulent Schmidt number $\left(\mathrm{Sc}_{\mathrm{t}}\right)$, defined as the ratio of momentum diffusivity to mass one in a turbulent flow. However, no universal value has been accepted for this parameter as it is a property of turbulent flows. The practical role of establishing a suitable $\mathrm{Sc}_{\mathrm{t}}$ in numerical studies of stormwater retention ponds is of the utmost importance because the assessment of the hydraulic efficiency of them is based on output mass concentration of tracer tests. In this study, several numerical simulations of a vortex-type stormwater retention pond were systematically carried out using FLOW-3D. A range of various turbulent Schmidt numbers were introduced in numerical simulations performed by different number of computational cells to investigate mesh sensitivity. Moreover, the effects of maximum turbulent mixing length as a user-defined or automatically computed value were assessed. The outcome of this study is an established numerical model with a constant value of maximum turbulent mixing length equal to $7 \%$ of the hydraulic diameter along with $\mathrm{Sc}_{\mathrm{t}}=0.625$ which provides a close agreement with experimental results. Noticeably, the peak values of numerical dimensionless RDT curves are dramatically decreased, resulted in a close match with experimental results. This concludes that FLOW-3D has a considerable ability to appropriately predict mass diffusivity in vortex-type physics of turbulent flows.
\end{abstract}

Keywords: turbulent Schmidt number - maximum turbulent mixing length - CFD - mesh sensitivity - vortex-type stormwater retention pond - environmental fluid mechanics

\section{Introduction}

Computational Fluid Dynamics (CFD) is deemed a potent tool to provide understanding and quantitative information in many complicated environmental flows. The role of inputs in reaching accurate and reliable CFD modelling results is highly important. When turbulence modelling is based on Reynolds-Averaged Navier-Stokes (RANS) equations, estimating the turbulent scalar transport requires the introduction of the turbulent Schmidt number $\left(\mathrm{Sc}_{\mathrm{t}}\right)$ as an extremely effective input. This determining parameter defined as the ratio of momentum diffusivity to mass one in a turbulent flow has no universal value and is the property of turbulent flow [1].

In one study [2], a tracer test was conducted, using three-dimensional simulations in a rectangular detention tank by assuming the turbulent Schmidt number of around 0.7. [3] applied CFD models to investigate flow and solute transport in disinfection tanks using the Multiphysics 3.2 ${ }^{\mathrm{TM}}$ and assumed $\mathrm{Sc}_{\mathrm{t}}=1$. A 3-D numerical modeling of stormwater retention ponds was run using ANSYS CFX 11.0 by [4]. Tracer transport simulations were carried out by adopting $\mathrm{Sc}_{\mathrm{t}}=0.7-0.8$ in their study. The flow and concentration field in rectangular tanks were studied using CFD simulations by [5]. The analysis of flow and concentration fields showed a good correlation between velocity and concentration gradient by assuming $\mathrm{Sc}_{\mathrm{t}}=0.7$. [6] applied CFD modelling to appraise a chlorine contact tank by varying turbulent Schmidt number and found that the best agreement between numerical and experimental results obtained with $\mathrm{Sc}_{\mathrm{t}}=1$. [7,8] utilized CFD method for numerical simulations of water disinfection contractors which tracer transport was carried out by assuming $\mathrm{Sc}_{\mathrm{t}}=0.7$. [9] indicated that 
since $\mathrm{Sc}_{\mathrm{t}}$ was dependent on the characteristics of the flow field, its value could be linked with the tank geometry. [10] experimentally and numerically studied the hydrodynamics and mixing processes in baffled disinfection tanks by introducing $\mathrm{Sc}_{\mathrm{t}}=$ 0.7. Reactive processes in disinfection contact tanks were investigated using three-dimensional numerical models by [11] and $\mathrm{Sc}_{\mathrm{t}}=0.7$ was suggested. [12] employed FLOW-3D and CORMIX for CFD modeling of two turbulent jet-tocrossflow cases including free surface jet impingement. They concluded that a RANS simulation with RNG k- $\varepsilon$ turbulence model along with $\mathrm{Sc}_{\mathrm{t}}=1.4$ gives reasonable results compared with experimental data. [13] conducted CFD modelling of residence times in vegetated stormwater ponds by assuming $\mathrm{Sc}_{\mathrm{t}}=1$. A CFD-based modeling framework for investigation of flow field, turbulence and mixing characteristics within vegetated environments such as ponds and wetlands is provided by [14] using ANSYS FLUENT 19. The turbulent Schmidt number was decomposed in their study into shear and wake components. $\mathrm{Sc}_{\mathrm{t}}=1$ and $\mathrm{Sc}_{\mathrm{t}}=0.2$ were introduced for shear and wake turbulent Schmidt numbers respectively.

In this study, the key role of the turbulent Schmidt number in numerical tracer tests of a vortex-type stormwater retention pond is investigated using FLOW-3D. Since the adequate value of this parameter depends on the property of a turbulent flow, vortex-type physics of this pond could be deemed to be noticeable. Numerical modelling was carried out to conduct a mesh sensitivity analysis by increasing the number of cells from 305870 to 406036 . In addition, the significant effects of introducing a constant value for maximum turbulent mixing length compared to dynamically computed one is assessed.

\section{Materials and Methods}

\subsection{Continuity Equation}

For a compressible Newtonian fluid, continuity equation is

$$
\frac{\partial \rho}{\partial t}=-\nabla \cdot(\rho \mathbf{u})
$$

where $\rho, \mathbf{u}$ and $\mathrm{t}$ are density, velocity vector and time respectively.

\subsection{Momentum Equation}

Momentum equation is described as:

$$
\rho \frac{D \mathbf{u}}{D t}=-\nabla \mathrm{P}+\mu \nabla^{2} \mathbf{u}+\mathrm{B}
$$

where $\rho, \mathbf{u}, \mathrm{P}, \mu$ and $\mathrm{B}$ are density, velocity vector, pressure, dynamic viscosity and body force respectively. $\frac{D}{D t}$ and $\nabla^{2}$ are material derivative and the Laplace operator respectively.

\subsection{Scalar Transport Equation}

Transport equation for scalar $\mathrm{C}$ within the turbulent flow field can be written in the following form:

$$
\frac{\partial \overline{\mathrm{C}}}{\partial \mathrm{t}}+\overline{\mathrm{u}} \frac{\partial \overline{\mathrm{C}}}{\partial \mathrm{x}}+\overline{\mathrm{v}} \frac{\partial \overline{\mathrm{C}}}{\partial \mathrm{y}}+\overline{\mathrm{w}} \frac{\partial \overline{\mathrm{C}}}{\partial \mathrm{z}}=\mathrm{D}_{\mathrm{t}-\mathrm{x}} \frac{\partial^{2} \overline{\mathrm{C}}}{\partial \mathrm{x}^{2}}+\mathrm{D}_{\mathrm{t}-\mathrm{y}} \frac{\partial^{2} \overline{\mathrm{C}}}{\partial \mathrm{y}^{2}}+\mathrm{D}_{\mathrm{t}-\mathrm{z}} \frac{\partial^{2} \overline{\mathrm{C}}}{\partial \mathrm{z}^{2}}
$$

The overbar indicates time-averaged quantities and $\mathrm{D}_{\mathrm{t}-\mathrm{x}}, \mathrm{D}_{\mathrm{t}-\mathrm{y}}$ and $\mathrm{D}_{\mathrm{t}-\mathrm{z}}$ are the turbulent diffusivities in the $\mathrm{x}, \mathrm{y}$ and $\mathrm{z}$ directions, respectively, of the scalar being transported by the turbulent flow. In Equation (3), the turbulent scalar fluxes based on Reynolds-Averaged Navier-Stokes (RANS) equations are mostly estimated by assuming the Standard Gradient Diffusion Hypothesis (SGDH) [15, 16]:

$$
\begin{aligned}
& \overline{\mathrm{u}^{\prime} \mathrm{C}^{\prime}}=-\mathrm{D}_{\mathrm{t}-\mathrm{x}} \frac{\partial \overline{\mathrm{C}}}{\partial \mathrm{x}} \\
& \overline{\mathrm{v}^{\prime} \mathrm{C}^{\prime}}=-\mathrm{D}_{\mathrm{t}-\mathrm{y}} \frac{\partial \overline{\mathrm{C}}}{\partial \mathrm{y}} \\
& \overline{\mathrm{w}^{\prime} \mathrm{C}^{\prime}}=-\mathrm{D}_{\mathrm{t}-\mathrm{z}} \frac{\partial \overline{\mathrm{C}}}{\partial \mathrm{z}}
\end{aligned}
$$


In Equation 4 to 6, u', v'and w'are fluctuating velocities in the $\mathrm{x}, \mathrm{y}, \mathrm{z}$ directions, respectively and C is fluctuating scalar concentration. The scalar Reynold fluxes connected to the spatial gradient of the time-averaged concentration through the turbulent diffusivity by the Standard Gradient Diffusion Hypothesis (SGDH). Turbulent Schmidt number $\left(\mathrm{Sc}_{\mathrm{t}}\right.$ ), is defined as:

$$
\mathrm{Sc}_{\mathrm{t}-\mathrm{i}}=\frac{\vartheta_{\mathrm{t}-\mathrm{i}}}{\mathrm{D}_{\mathrm{t}-\mathrm{i}}}
$$

where $v_{\mathrm{t}-\mathrm{i}}$ is the eddy kinematic viscosity in the $\mathrm{i}$-th direction. Hence, if the turbulent Schmidt number is known, the turbulent diffusivities can be estimated as [1]:

\subsection{Experimental Model and Tests}

$$
\mathrm{D}_{\mathrm{t}-\mathrm{i}}=\frac{\vartheta_{\mathrm{t}-\mathrm{i}}}{\mathrm{Sc}_{\mathrm{t}-\mathrm{i}}}
$$

Figure 1 represents the experimental model. The model was circular in plan constructed with the slope of the sides and the diameter of bottom circle, $3 \mathrm{H}: 1 \mathrm{~V}$ and $2.859 \mathrm{~m}$ respectively. The flow rate for the model was $0.76 \mathrm{~L} / \mathrm{s}$ and diameters of the inlet and outlet were $52 \mathrm{~mm}$ and $59 \mathrm{~mm}$, respectively. The inlet or inflow entered the pond along its periphery and the longitudinal axis of the inlet pipe made a $30^{\circ}$ angle with a tangent line to the pond circumference at the point of entrance and was projected about $300 \mathrm{~mm}$ into the model [17].

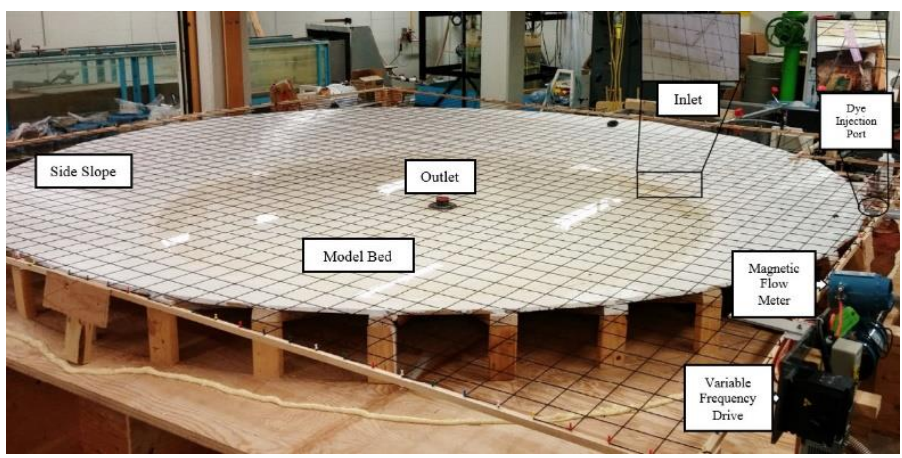

Figure 1- The experimental model [17]

For the tracer tests, Rhodamine WT was used as tracer material and $30 \mathrm{~mL}$ of $1190 \mathrm{ppm}$ Rhodamine WT was injected into the inflow of the model [17].

\subsection{Numerical Model}

Numerical modelling was carried out using FLOW-3D. The inlet was introduced into the pond by a mass-momentum source and exited through a mass-momentum sink at the center where both inlet and outlet flow rates were determined to be 0.76 liters per second (equivalent to the experimental model). Inlet and outlet are shown schematically in Figure 2. RNG k$\varepsilon$ was implemented to properly simulate the swirling flow pattern [18]. Symmetrical boundary conditions in different directions were selected and the initial pressure condition at the inlet was uniform. Several different numbers of computational cells were used 305870, 350460 and 406036 To check the sensitivity of the results to the mesh size. Nonuniform meshing was applied in all numerical models which have two mesh blocks. First mesh block is used for general domain and the second one provides high accuracy in the outlet area where the output tracer concentration of model is measured using a flux surface offered by FLOW-3D. Positioning of mesh blocks is shown in Figure 3. The range of turbulent Schmidt numbers was selected from 0.5 to 1 depending on how the numerical output mass concentrations were in an agreement with those of experiment. 


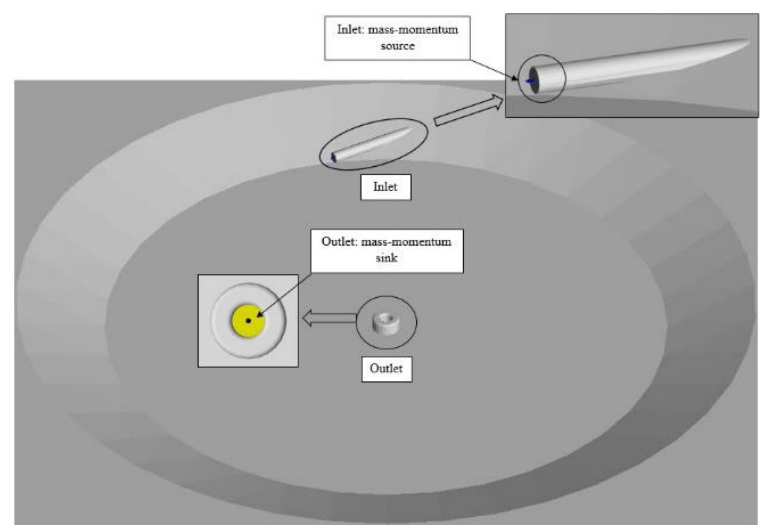

Figure 2- Schematic of boundary conditions in the numerical model

There are two methods for calculating the maximum turbulent mixing length in FLOW-3D: (1) dynamically calculation as the default; and (2) defining a constant value by the users. The latter is recommended to be determined equal to $7 \%$ of the hydraulic diameter [19] which is the depth in this study (e.g. $0.00455=7 \%$ of flow depth equal to $65 \mathrm{~mm}$ ). The effects of applying both methods on dimensionless RTD curves are of importance in this study, so after obtaining the acceptable results from first method, maximum turbulent mixing length was adjusted to the constant value in the second method and the effects on numerical results were investigated. More details are explained in section 3.

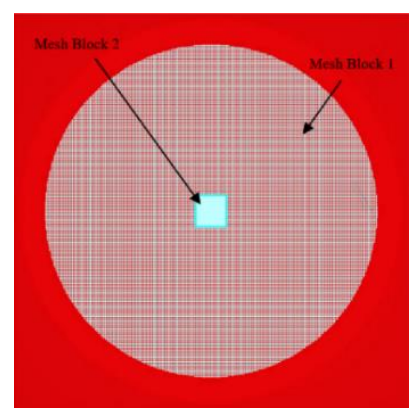

Figure 3- Positioning of mesh blocks

\section{Results and Discussions}

Two types of errors such as relative error and root mean square error (RMSE) were used to compare the numerical results with the experimental ones. Relative error was implemented to compare numerical and experimental results of parameters such as baffle factor, mean retention time index, Morrill dispersion index, short circuiting index and modal detention time index. Moreover, root mean square error (RMSE) method was used to compare the results of numerical and experimental dimensionless RTD curves. The dimensionless RTD function, $\mathrm{E}_{\theta}$, is

$$
\begin{gathered}
E_{\theta}=E(t) t_{d} \\
E(t)=\frac{C(t)}{\int_{0}^{\infty} C(t) d t}=\frac{Q C(t)}{M}
\end{gathered}
$$

Where $\mathrm{C}(\mathrm{t}), \mathrm{Q}, \mathrm{M}$ and $\mathrm{t}$ are the concentration, flow rate, total tracer mass and time from the injection of tracer respectively. $t_{d}$ is defined as theoretical retention time determined from the ratio of system volume to the flow rate [17].

The baffle factor and the mean detention time indices are the ratio of the time for passing $10 \%$ and $50 \%$ of the dye through the outlet to $t_{d}$, respectively. The Morril dispersion index is the ratio of the time for $90 \%$ of the dye to pass through the outlet to the time for $10 \%$ of the dye to pass through the outlet. The short-circuiting index is ratio of the time for first 
observation of dye at the outlet to $t_{\mathrm{d}}$. The modal retention time index is defined as the ratio of the time to reach peak concentration to the theoretical retention time $[20,21]$.

\subsection{Modelling Results without Constant Maximum Turbulent Mixing Length}

In the following subsections, the results of mesh sensitivity analysis will be illustrated in which the least RMSE in comparison with other models is merely explained in detail to shorten the length of manuscript.

\subsubsection{Numerical model with 305870 computational cells}

Several numerical tests with various turbulent Schmidt numbers ranging from 0.5 to 1 were carried out by this model since it has the least computational cells and simulation time. Relative errors are shown in table 1.

RMSE values for numerical models with $\mathrm{Sc}_{\mathrm{t}}$ equal to 1, 0.85, 0.75, 0.7, 0.6 and 0.5 are 17.95, 14.84, 12.61, 11.5, 9.53 and $8.69 \%$ respectively. The peak value of numerical dimensionless RTD curve was predicted $16.25 \%$ higher than that of the experiment by $\mathrm{Sc}_{\mathrm{t}}=0.5$ which was the least among numerical models with 305870 computational cells.

Table 1- The comparison between numerical and experimental results of output concentration parameters with 305870 cells

\begin{tabular}{|c|c|c|c|c|c|c|c|c|c|c|c|c|c|}
\hline \multirow{3}{*}{ parameter } & \multirow{3}{*}{$\begin{array}{l}\text { Experimental } \\
\text { results }\end{array}$} & \multicolumn{12}{|c|}{ Numerical results } \\
\hline & & \multicolumn{2}{|c|}{$\mathrm{Sc}_{\mathrm{t}}=0.5$} & \multicolumn{2}{|c|}{$\mathrm{Sc}_{\mathrm{t}}=0.6$} & \multicolumn{2}{|c|}{$\mathrm{Sc}_{\mathrm{t}}=0.7$} & \multicolumn{2}{|c|}{$\mathrm{Sc}_{\mathrm{t}}=0.75$} & \multicolumn{2}{|c|}{$\mathrm{Sc}_{\mathrm{t}}=0.85$} & \multicolumn{2}{|l|}{$\mathrm{Sc}_{\mathrm{t}}=1$} \\
\hline & & value & $\begin{array}{l}\text { Error } \\
(\%)\end{array}$ & value & $\begin{array}{l}\text { Error } \\
(\%)\end{array}$ & value & $\begin{array}{l}\text { Error } \\
(\%)\end{array}$ & value & $\begin{array}{l}\text { Error } \\
(\%)\end{array}$ & value & $\begin{array}{l}\text { Error } \\
(\%)\end{array}$ & value & $\begin{array}{l}\text { Error } \\
(\%)\end{array}$ \\
\hline Baffle Factor & 0.42 & 0.454 & 8.10 & 0.438 & 4.30 & 0.424 & 1.00 & 0.418 & 0.50 & 0.408 & 2.90 & 0.394 & 6.20 \\
\hline $\begin{array}{l}\text { Index of mean } \\
\text { detention time }\end{array}$ & 0.86 & 0.832 & 3.30 & 0.813 & 5.50 & 0.797 & 7.30 & 0.789 & 8.30 & 0.775 & 9.90 & 0.757 & 12.00 \\
\hline $\begin{array}{l}\text { Morril dispersion } \\
\text { index }\end{array}$ & 4.1 & 3.874 & 5.50 & 4.107 & 0.20 & 4.319 & 5.30 & 4.414 & 7.70 & 4.586 & 11.90 & 4.818 & 17.50 \\
\hline $\begin{array}{l}\text { Short-circuiting } \\
\text { index }\end{array}$ & 0.21 & 0.223 & 6.20 & 0.218 & 3.80 & 0.215 & 2.40 & 0.213 & 1.40 & 0.209 & 0.50 & 0.205 & 2.40 \\
\hline $\begin{array}{l}\text { Index of modal } \\
\text { detention time }\end{array}$ & 0.57 & 0.581 & 1.90 & 0.552 & 3.20 & 0.523 & 8.20 & 0.523 & 8.20 & 0.495 & 13.20 & 0.466 & 18.20 \\
\hline
\end{tabular}

\subsubsection{Numerical model with 350460 computational cells}

Numerical results of output concentration parameters are shown in table 2. The peak value of dimensionless RTD curve predicted by numerical model with $\mathrm{Sc}_{\mathrm{t}}=0.5$ was $16.69 \%$ higher than experimental result which is the best among other simulations with 350460 computational cells. RMSE values of dimensionless RTD curves for numerical models with Sc $\mathrm{c}_{\mathrm{t}}$ equal to $0.7,0.6$ and 0.5 are $11.90,9.88$ and $8.93 \%$ respectively.

Table 2- The comparison between numerical and experimental results of output concentration parameters with 350460 cells

\begin{tabular}{|l|l|l|l|l|l|l|l|}
\hline \multirow{2}{*}{ Parameter } & \multirow{2}{*}{ Experimental results } & \multicolumn{2}{|l|}{ Numerical results } \\
\cline { 3 - 8 } & & $\mathrm{Sc}_{\mathrm{t}}=0.5$ & $\mathrm{Sc}_{\mathrm{t}}=0.6$ & \multicolumn{2}{l|}{$\mathrm{Sc}_{\mathrm{t}}=0.7$} \\
\cline { 3 - 8 } & & value & $\begin{array}{l}\text { Error } \\
(\%)\end{array}$ & value & $\begin{array}{l}\text { Error } \\
(\%)\end{array}$ & value & $\begin{array}{l}\text { Error } \\
(\%)\end{array}$ \\
\hline Baffle Factor & 0.42 & 0.454 & 8.10 & 0.438 & 4.30 & 0.424 & 1.00 \\
\hline Index of mean detention time & 0.86 & 0.831 & 3.40 & 0.811 & 5.70 & 0.795 & 7.60 \\
\hline Morril dispersion index & 4.1 & 4.344 & 6.00 & 4.115 & 0.40 & 4.327 & 5.50 \\
\hline Short-circuiting index & 0.21 & 0.225 & 7.10 & 0.220 & 4.80 & 0.216 & 2.90 \\
\hline Index of modal detention time & 0.57 & 0.581 & 1.90 & 0.552 & 3.20 & 0.523 & 8.20 \\
\hline
\end{tabular}




\subsubsection{Numerical model with 406036 computational cells}

Numerical results of output mass concentrations along with relative errors compared to experimental ones are shown in table 3. Numerical dimensionless RTD of models with $\mathrm{Sc}_{\mathrm{t}}$ equal to 0.7, 0.6 and 0.5 are provided for different simulations with 305870, 350460 and 406036 computational cells and the result for 406036 computational cells is shown in Figure 4. The peak value of numerical dimensionless RTD curve was predicted as $12.60 \%$ higher than experimental one for simulation with $\mathrm{Sc}_{\mathrm{t}}=0.5$. This is the best result compared to other simulations carried out by 406036 computational cells with different turbulent Schmidt numbers. RMSE values for numerical models with $\mathrm{Sc}_{\mathrm{t}}$ equal to 0.7, 0.6 and 0.5 were 13.59, 10.51 and $7.55 \%$ respectively.

Table 3- The comparison between numerical and experimental results of output concentration parameters with 406036

\begin{tabular}{|c|c|c|c|c|c|c|c|}
\hline \multirow{3}{*}{ Parameter } & \multirow{3}{*}{ Experimental results } & \multicolumn{6}{|c|}{ Numerical results } \\
\hline & & \multicolumn{2}{|c|}{$\mathrm{Sc}_{\mathrm{t}}=0.5$} & \multicolumn{2}{|c|}{$\mathrm{Sc}_{\mathrm{t}}=0.6$} & \multicolumn{2}{|c|}{$\mathrm{Sc}_{\mathrm{t}}=0.7$} \\
\hline & & value & $\begin{array}{l}\text { Error } \\
(\%)\end{array}$ & value & $\begin{array}{l}\text { Error } \\
(\%)\end{array}$ & value & $\begin{array}{l}\text { Error } \\
(\%)\end{array}$ \\
\hline Baffle Factor & 0.42 & 0.429 & 2.10 & 0.412 & 1.90 & 0.399 & 5.00 \\
\hline Index of mean detention time & 0.86 & 0.821 & 4.50 & 0.801 & 6.90 & 0.783 & 9.00 \\
\hline Morril dispersion index & 4.1 & 4.215 & 2.80 & 4.476 & 9.20 & 4.395 & 7.19 \\
\hline Short-circuiting index & 0.21 & 0.203 & 3.30 & 0.199 & 5.20 & 0.196 & 6.20 \\
\hline Index of modal detention time & 0.57 & 0.552 & 3.20 & 0.523 & 8.20 & 0.495 & 13.20 \\
\hline
\end{tabular}

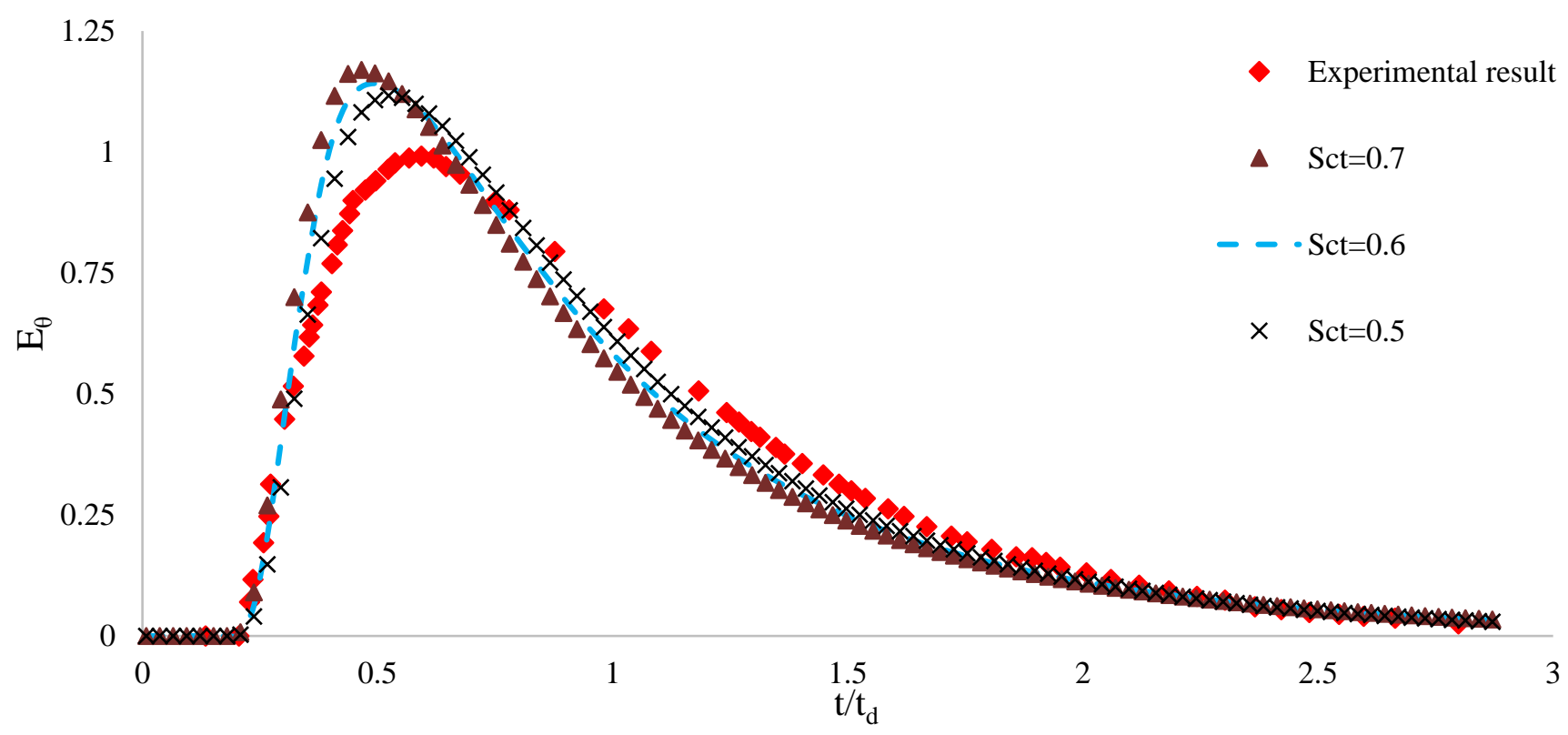

Figure 4- Comparison between numerical and experimental results of dimensionless RTD curves (406036 cells)

\subsubsection{Discussion about modelling Results without Constant Maximum Turbulent Mixing Length}

Regarding each numerical model with a certain number of computational cells, the value of output concentration parameters (e.g. baffle factor, index of mean detention time, short-circuiting index and index of modal detention time) are inversely related to $\mathrm{Sc}_{\mathrm{t}}$. Since turbulent mass diffusivity is inversely related to $\mathrm{Sc}_{t}$, introducing higher values of $\mathrm{Sc}_{\mathrm{t}}$ causes a decrease in turbulent tracer diffusion. This can cause a condition in vortex-type physics of this pond that not only does a larger mass of tracer pass through the outlet in a shorter duration, but numerical models also predict a shorter time which is required for the first tracer particle to reach the central outlet. 
Additionally, considering the results of RMSE and relative error values for numerical simulations with different computational cells (305870, 350460 and 406036), the model with 406036 cells and $\mathrm{Sc}_{\mathrm{t}}=0.5$ had the least RMSE in comparison with other models $(7.55 \%)$ and predicted the reasonable peak value for dimensionless RTD curve among the rest (relative error equal to $12.60 \%$ ). Furthermore, relative errors regarding output concentration parameters were under 5\% which shows that this model can efficiently predict the trend of output tracer mass. As a result, this numerical model was selected for investigating the role of a constant value for maximum turbulent mixing length (based on second method mentioned in section 2.5).

\subsection{Modelling Results with Constant Maximum Turbulent Mixing Length}

Numerical modeling with a constant maximum turbulent mixing length equal to $7 \%$ of the hydraulic diameter (i.e. $0.00455 \mathrm{~m}$ in this case) were carried out and results are shown in table 4 and Figure 5.

Table 4- The comparison between numerical and experimental results of output concentration parameters with 406036 cells and constant turbulent mixing length equal to $0.00455 \mathrm{~m}$

\begin{tabular}{|c|c|c|c|c|c|c|c|c|c|c|c|c|c|}
\hline \multirow{3}{*}{ parameter } & \multirow{3}{*}{$\begin{array}{l}\text { Experimental } \\
\text { results }\end{array}$} & \multicolumn{12}{|c|}{ Numerical results } \\
\hline & & \multicolumn{2}{|c|}{$S c_{t}=0.4$} & \multicolumn{2}{|c|}{$\mathrm{Sc}_{\mathrm{t}}=0.5$} & \multicolumn{2}{|c|}{$S c_{t}=0.6$} & \multicolumn{2}{|c|}{$\mathrm{Sc}_{\mathrm{t}}=0.625$} & \multicolumn{2}{|c|}{$\mathrm{Sc}_{\mathrm{t}}=0.65$} & \multicolumn{2}{|c|}{$\mathrm{Sc}_{\mathrm{t}}=0.7$} \\
\hline & & value & $\begin{array}{l}\text { Error } \\
(\%)\end{array}$ & value & $\begin{array}{l}\text { Error } \\
(\%)\end{array}$ & value & $\begin{array}{l}\text { Error } \\
(\%)\end{array}$ & value & $\begin{array}{l}\text { Error } \\
(\%)\end{array}$ & value & $\begin{array}{l}\text { Error } \\
(\%)\end{array}$ & value & $\begin{array}{l}\text { Error } \\
(\%)\end{array}$ \\
\hline Baffle Factor & 0.42 & 0.496 & 18.10 & 0.467 & 11.20 & 0.444 & 5.70 & 0.439 & 4.50 & 0.434 & 3.30 & 0.425 & 1.20 \\
\hline $\begin{array}{l}\text { Index of mean } \\
\text { detention time }\end{array}$ & 0.86 & 0.901 & 4.80 & 0.885 & 2.90 & 0.869 & 1.00 & 0.865 & 0.60 & 0.861 & 0.1 & 0.853 & 0.80 \\
\hline $\begin{array}{l}\text { Morril dispersion } \\
\text { index }\end{array}$ & 4.1 & 3.293 & 19.70 & 3.606 & 12.00 & 3.901 & 4.80 & 3.971 & 3.10 & 4.041 & 1.40 & 4.177 & 1.90 \\
\hline $\begin{array}{l}\text { Short-circuiting } \\
\text { index }\end{array}$ & 0.21 & 0.215 & 38.20 & 0.208 & 0.95 & 0.202 & 3.81 & 0.201 & 4.30 & 0.198 & 5.70 & 0.196 & 6.70 \\
\hline $\begin{array}{l}\text { Index of modal } \\
\text { detention time }\end{array}$ & 0.57 & 0.695 & 21.90 & 0.666 & 16.80 & 0.609 & 6.90 & 0.581 & 1.90 & 0.581 & 1.90 & 0.552 & 3.20 \\
\hline
\end{tabular}

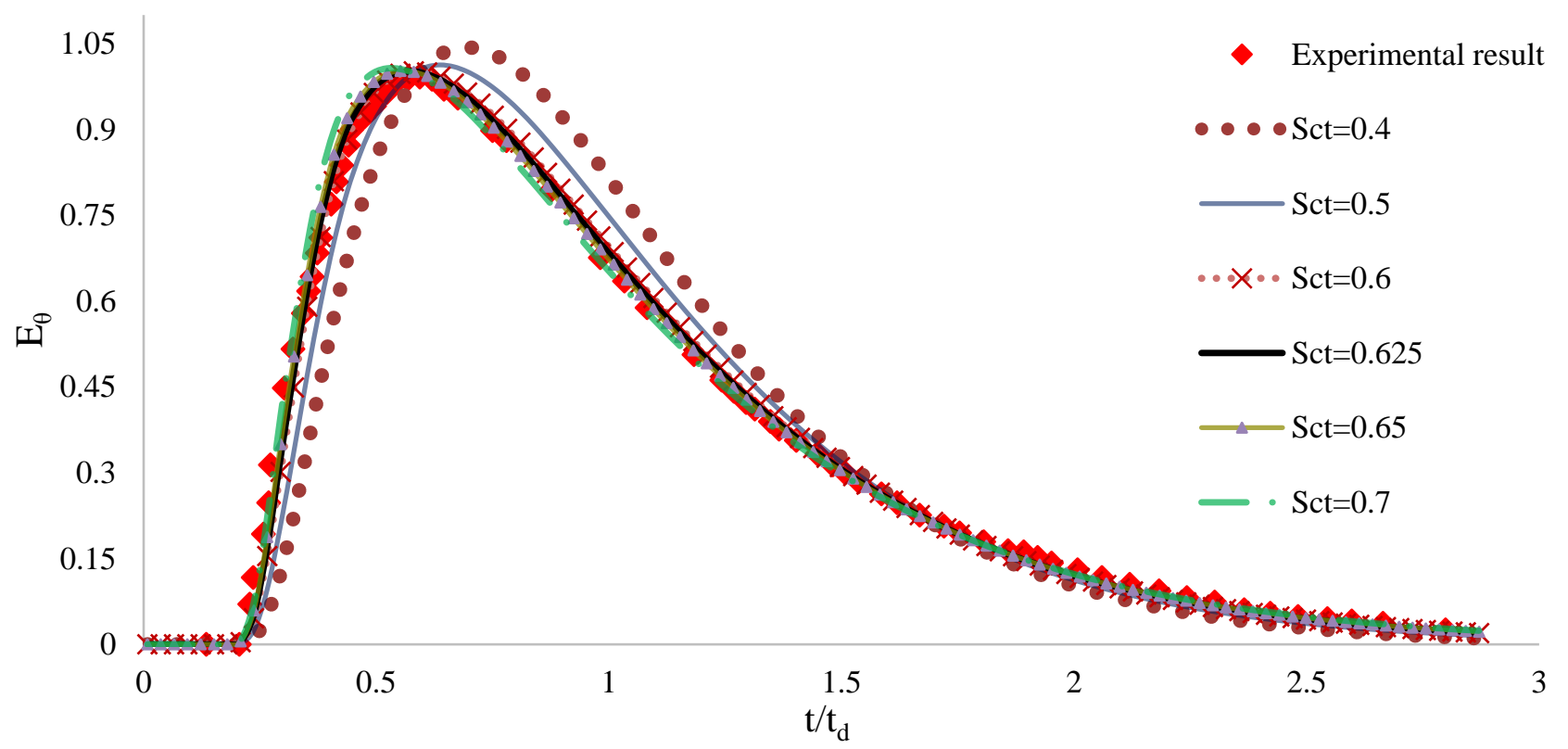

Figure 5- Comparison between numerical and experimental results of dimensionless RTD curves (cell number= 406036, Sct ranging from 0.4 to 0.7 and constant turbulent mixing length $=0.00455 \mathrm{~m}$ ) 
RMSE values for numerical models performed by $\mathrm{Sc}_{\mathrm{t}}$ equal to $0.4,0.5,0.6,0.625,0.65$ and 0.7 were $12.60,7.04,3.10$, $2.75,2.88$ and $4.10 \%$ respectively. In addition, the relative error in predicting the peak of dimensionless RTD curve in numerical modeling simulated by $\mathrm{Sc}_{\mathrm{t}}$ equal to $0.4,0.5,0.6,0.625,0.65$ and 0.7 were $5.4,2.91,1.70,1.50,1.62$ and $1.91 \%$ respectively. By comparing Figure 5 with 4, there are two noticeable differences between numerical results of dimensionless RTD curves related to two sets of simulations carried out by applying a constant maximum turbulent mixing length (equal to $7 \%$ of the hydraulic diameter) and dynamically computed one respectively. The first important difference is associated with the peak of dimensionless RTD curves which seems to be much more reasonably attenuated by numerical model. This peak attenuation causes more precise dimensionless RTD curves whose RMSEs are remarkably less than those derived from first set. This shows that introducing the constant value for maximum turbulent mixing length improves the prediction of scalar transport. This means applying a constant maximum turbulent mixing length equal to $7 \%$ of hydraulic diameter along with establishing an appropriate $\mathrm{Sc}_{\mathrm{t}}$ results in a reasonable prediction of mass diffusivity by numerical model in FLOW-3D especially in vortex-type flows.

Among these numerical simulations performed by the maximum turbulent mixing length equal to $7 \%$ of the hydraulic diameter (i.e. $0.00455 \mathrm{~m}$ in this case), numerical model with turbulent Schmidt number equal to 0.625 is in a close agreement with experimental results. The relative errors of the output concentration parameters are under $5 \%$ as can be seen in table 4 . This model creates the least RMSE value of $2.75 \%$ which indicates how powerful and efficient FLOW-3D is in simulating vortex-type flows.

\section{Conclusion}

In this study, a numerical modelling of a vortex-type retention pond was performed in which the number of cell was increased from 305870 to 406036 with three intervals to investigate mesh sensitivity using FLOW-3D. Two mesh blocks were used to provide adequate resolution particularly in the outlet area of the pond. RNG k- $\varepsilon$ was used for turbulence modelling and a various range of $\mathrm{Sc}_{\mathrm{t}}$ from 0.4 to 1 was introduced as inputs. In the first set of numerical tests, maximum turbulent mixing length was automatically calculated by FLOW-3D and numerical output mass concentration of each model were compared to experimental results. Numerical modelling with 406036 cells and $\mathrm{Sc}_{\mathrm{t}}=0.5$ was in an acceptable agreement with experimental results since the values of RMSE of dimensionless RDT curve and maximum relative error of output mass concentration parameters were $7.55 \%$ and $4.5 \%$ respectively. This model was used in the second set and unlike the first set a constant value of maximum turbulent mixing length equal to $7 \%$ of the hydraulic diameter (i.e. $0.00455 \mathrm{~m}$ calculated for this study) was applied. It was shown that a numerical model with $\mathrm{Sc}_{\mathrm{t}}=0.625$ was in the best agreement with experimental results because maximum relative error of the output concentration parameters and the value of RMSE were $4.5 \%$ and $2.75 \%$ respectively. Noticeably, comparing the outcome of first and second sets, the peak values of numerical dimensionless RDT curves decrease from $12.6 \%$ to $1.5 \%$. It also indicates that FLOW-3D has a considerable ability to appropriately predict mass diffusivity in vortex-type physics of turbulent flows.

\section{References}

[1] C. Gualtieri, A. Angeloudis, F. Bombardelli, S. Jha, and T. Stoesser, "On the Values for the Turbulent Schmidt Number in Environmental Flows," Fluids, vol. 2, p. 17, 2017.

[2] A. Adamsson, L. Bergdahl, and S. Lyngfelt, "Measurement and three-dimensional simulation of flow in a rectangular detention tank," Urban Water Journal, vol. 2, no. 4, pp. 277-287, 2005/12/01 2005, doi: 10.1080/15730620500386545.

[3] C. Gualtieri, "Numerical simulation of flow and tracer transport in a disinfection contact tank," 2006.

[4] S. Khan, B. Melville, and A. Shamseldin, Modeling the Layouts of Stormwater Retention Ponds using Residence Time. 2009, pp. 77-83.

[5] F. Martínez-Solano, P. L. I. Rey, C. Gualtieri, and P. López-Jiménez, "Modelling flow and concentration field in rectangular water tanks," 2010.

[6] W. B. Rauen, A. Angeloudis, and R. A. Falconer, "Appraisal of chlorine contact tank modelling practices," Water Research, vol. 46, no. 18, pp. 5834-5847, 2012/11/15/ 2012, doi: https://doi.org/10.1016/j.watres.2012.08.013. 
[7] J. Zhang, A. Tejada-Martínez, and Q. Zhang, "Evaluation of LES and RANS for Determining Hydraulic Performance of Disinfection Systems for Water Treatment," Journal of Fluids Engineering, vol. 136, 05/15 2014, doi: $10.1115 / 1.4027652$.

[8] J. Zhang, A. E. Tejada-Martínez, and Q. Zhang, "Developments in computational fluid dynamics-based modeling for disinfection technologies over the last two decades: A review," Environmental Modelling \& Software, vol. 58, pp. 7185, 2014/08/01/ 2014, doi: https://doi.org/10.1016/j.envsoft.2014.04.003.

[9] C. Gualtieri and F. Salzano, "DIscussion on "The effect of baffle spacing on hydrodynamics and solute transport in serpentine contact tanks"," Journal of Hydraulic Research, vol. 52, pp. 152-154, 02/28 2014, doi: 10.1080/00221686.2013.877528.

[10] A. Angeloudis, T. Stoesser, R. A. Falconer, and D. Kim, "Flow, transport and disinfection performance in small- and full-scale contact tanks," Journal of Hydro-environment Research, vol. 9, no. 1, pp. 15-27, 2015/03/01/ 2015, doi: https://doi.org/10.1016/j.jher.2014.07.001.

[11] A. Angeloudis, T. Stoesser, C. Gualtieri, and R. A. Falconer, "Contact Tank Design Impact on Process Performance," Environmental Modeling \& Assessment, vol. 21, no. 5, pp. 563-576, 2016/10/01 2016, doi: 10.1007/s10666-016-9502$\mathrm{x}$.

[12] D. Valero and D. B. Bung, "Sensitivity of turbulent Schmidt number and turbulence model to simulations of jets in crossflow," Environmental Modelling \& Software, vol. 82, pp. 218-228, 2016/08/01/ 2016, doi: https://doi.org/10.1016/j.envsoft.2016.04.030.

[13] F. Sonnenwald, I. Guymer, and V. Stovin, "Computational fluid dynamics modelling of residence times in vegetated stormwater ponds," Proceedings of the Institution of Civil Engineers - Water Management, vol. 171, pp. 1-11, 11/07 2017, doi: 10.1680/jwama.16.00117.

[14] F. Sonnenwald, I. Guymer, and V. Stovin, "A CFD-Based Mixing Model for Vegetated Flows," Water Resources Research, vol. 55, no. 3, pp. 2322-2347, 2019, doi: https://doi.org/10.1029/2018WR023628.

[15] S. B. Pope, Turbulent Flows. Cambridge, UK: Cambridge University Press, 2000.

[16] R. Rossi and G. Iaccarino, "Numerical simulation of scalar dispersion downstream of a square obstacle using gradienttransport type models," Atmospheric Environment, vol. 43, no. 16, pp. 2518-2531, 2009/05/01/ 2009, doi: https://doi.org/10.1016/j.atmosenv.2009.02.044.

[17] R. Chowdhury, M. Ahadi, K. A. Mazurek, G. Putz, D. Bergstrom, and C. Albers, "Physical Scale and Computational Modeling in the Development of a Vortex-Type Stormwater Retention Pond," in World Environmental and Water Resources Congress 2016, 2016, pp. 388-397.

[18] V. Yakhot and L. M. Smith, "The renormalization group, the $\varepsilon$-expansion and derivation of turbulence models," Journal of Scientific Computing, vol. 7, no. 1, pp. 35-61, 1992/03/01 1992, doi: 10.1007/BF01060210.

[19] Flow Science, Inc., FLOW-3D User manual. Santa Fe, NM, USA. (2015).

[20] M. M. Bishop, J. M. Morgan, B. Cornwell, and D. K. Jamison, "Improving the Disinfection Detention Time of a Water Plant Clearwell," Journal AWWA, vol. 85, no. 3, pp. 68-75, 1993, doi: https://doi.org/10.1002/j.15518833.1993.tb05958.x.

[21] F. L. Hart, "Improved Hydraulic Performance of Chlorine Contact Chambers.," Jounal of Water Pollution Control Federation, vol. 51(12), pp. 2868-2875, 1979. 